\title{
Development status and suggestions of Natural Gas Power Generation Industry in China
}

\author{
Sun $\mathrm{Li}^{1}{ }^{1}$ * Li Hongmei ${ }^{2} \quad$ Xing Jinyan ${ }^{1} \quad$ Pan Yun ${ }^{1}$ \\ ${ }^{1}$ China Huadian Group Clean Energy Co., Ltd., Beijing 100160 China \\ ${ }^{2}$ Zhongyuan Oilfield Natural Gas treatment Plant, Puyang, Henan 457001 China
}

\begin{abstract}
At present, the development speed of natural gas power generation in China lags far behind the world average level, and there are many problems in the gas electricity industry, including the high gas price of natural gas is difficult to dredge the electricity price, the online electricity quantity is difficult to guarantee, the natural gas supply has the bottleneck, the power plant lacks the bargaining right and so on, which seriously restricts the healthy and sustainable development of the natural power generation industry. On the basis of combing and investigating the existing problems of natural gas power generation in China, this paper expounds the orientation and goal of the development of China's natural gas power generation industry, and puts forward some concrete suggestions for promoting the development of China's natural gas power generation industry.
\end{abstract}

\section{Introduction}

Natural gas power generation has the characteristics of clean and environmental protection, which plays an important role in improving the atmospheric environment and improving the primary energy structure of China. Natural gas power generation accounts for about $23 \%$ of the world's power generation in 2018, while China's natural gas power generation accounts for only $4.65 \%$ of China's power generation. The development speed of gas and electricity in China lags far behind the world average. On the one hand, China's economic development is at the level of developing countries, on the other hand, China's natural gas industry is also in the development stage, and the infrastructure needs to be improved. The development of gas and electricity in China depends on the orientation and support of policies, as well as on the investment of power generation enterprises in the development of gas and electricity. China should position the strategic position of gas electricity in the field of power generation in China as soon as possible and formulate development plans so as to speed up the development of China's gas and electricity industry.

\section{Development status and prospect of natural gas industry in China}

\subsection{Development status and regional distribution of natural gas power generation industry in China}

In recent years, driven by the national environmental protection policy, China's natural gas power generation capacity and power generation have been increasing. In 2018 , the national natural gas power generation capacity was 88.07 million kilowatts, accounting for about 4.65 percent of the country's total installed power capacity, 271 billion kilowatt-hours of electricity generation, accounting for about 4.0 percent of the country's total power generation(Fig. 1.1). 


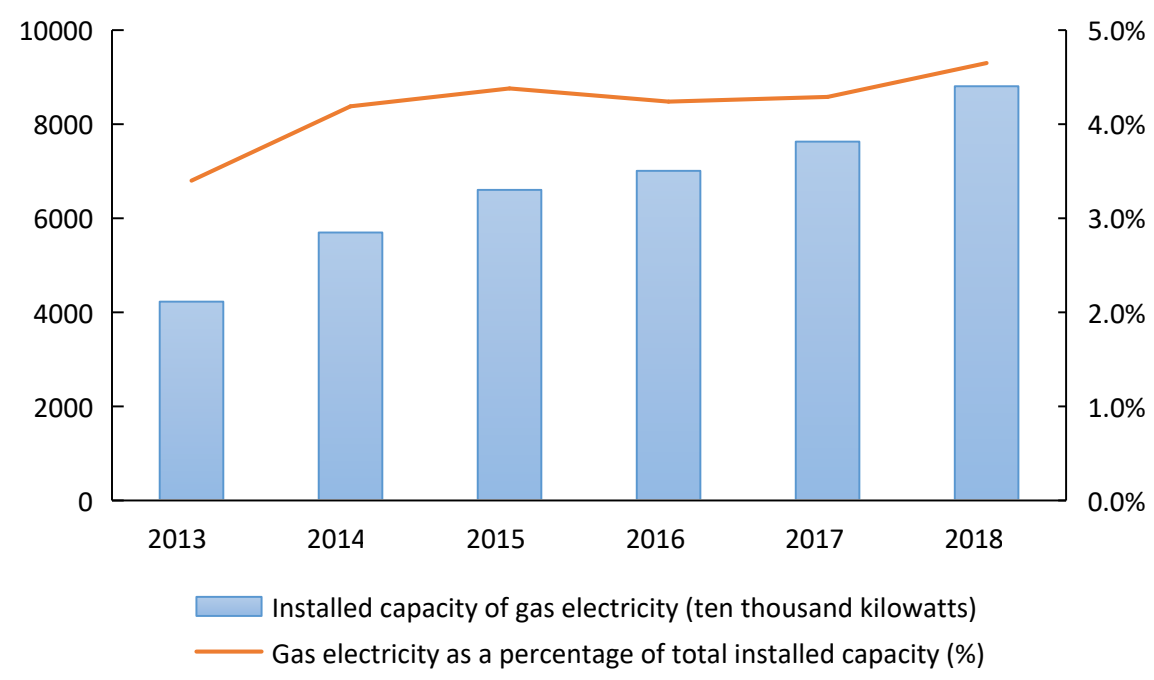

Fig. 1.1 installed capacity of natural gas power generation in China and its proportion to total installed capacity

Judging from the gas consumption of gas and electricity, the apparent consumption of natural gas in China was 274 billion cubic meters in 2018, an increase of 14.5 percent over the same period last year, of which the proportion of gas used for natural gas power generation reached 18 percent of the total natural gas consumption. In fact, the growth rate of gas and electricity consumption is closely related to natural gas price and gas and electricity policy. In 2015, the price of natural gas gate station in China was adjusted twice, and the adjustment range at the end of the year was as high as 0.7 yuan / cubic meter, which stimulated the consumption of terminal natural gas to a certain extent, and the gas and electricity consumption was also affected. At the same time, in 2017, the state promulgated "speeding up the promotion of natural gas utilization." It is proposed that "vigorously develop natural gas distributed energy, encourage the development of natural gas peak-shaving power stations, and develop natural gas cogeneration in an orderly manner." the development of gas and electricity industry has rebounded. In 2018,
China's natural gas power generation consumption reached 49.32 billion cubic meters, accounting for 18 percent of the total natural gas consumption, which is basically stable compared with 2017.

From the regional distribution of natural gas power generation in China, natural gas power generation in China is mainly distributed in the Yangtze River Delta, southeast coastal and other economically developed provinces and cities. There are also some gas power plants in Beijing, Tianjin and central and southern China. In addition, there are a small number of self-owned gas power plants around the oil and gas fields in the western region. Among them, the installed capacity of gas power plants in Guangdong, Fujian and Hainan provinces accounts for $34 \%$ of the total installed capacity of gas power generation in China, about $32 \%$ in Jiangsu, Zhejiang and Shanghai, and about $23 \%$ in Beijing and Tianjin. The total proportion of the above areas is nearly $90 \%$, and the regional development imbalance of gas and electricity industry is remarkable(Fig. 1.2 ).

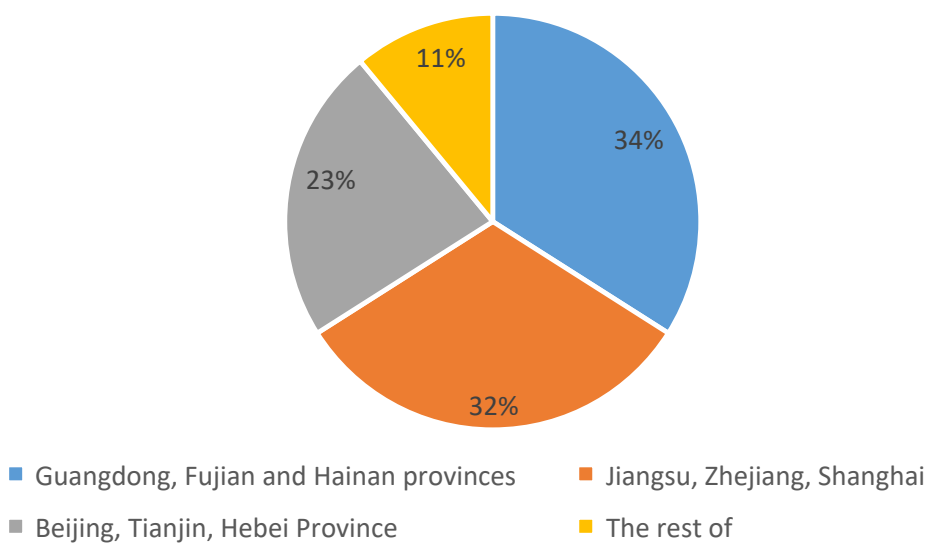

Fig. 1.2 Regional distribution of installed capacity of natural gas power plants in China

\subsection{Status of natural gas power generation industry chain in China}

The industrial chain of natural gas power generation industry in China is composed of four main links. The first link is the gas supply side, in which, according to 
different modes of gas source supply, the main body of gas supply may be domestic gas fields, imported pipelines, imported LNG direct gas supply, or provincial pipeline network companies responsible for gas supply, or local urban gas companies responsible for gas supply. Upstream direct gas supply enterprises are PetroChina, Sinopec, CNOOC, Jiufeng, Guanghui, etc. Provincial pipeline network companies include Zhejiang Province pipe network, Guangdong Province pipeline network, etc. Local urban gas companies mainly include China Gas, Hong Kong and China Gas, Xinao Gas, China Resources Gas and Kunlun Gas. Second ring Section is the power generation enterprises responsible for investment and operation of gas power plants, upward gas suppliers to buy natural gas into electricity. At present, China's natural gas power generation operations are mainly divided into three categories: the first is the state-owned large power generation central enterprises, such as Huadian Group, Huaneng Group, Datang Group, China Electric Power Investment Group and so on. The second category is local government investment groups and energy groups, such as Shenneng Group, Zhejiang Neng Group, Guoxin Group and Jingneng Group. The third category is oil, natural gas production and supply companies: such as China Petrochemical Group and China Petroleum Gas Group. In order to take advantage of their respective advantages and realize complementary advantages, most gas power plants For the joint venture construction. The third link is the power grid company in charge of transmission. The power generated by the power plant is supplied to the downstream grid company according to the feed-in electricity price. The power grid company includes the state grid, the southern power grid and so on. The fourth link is the power end user, according to the sales price to buy power resources, its user types include residents, industry, commerce and so on.

\subsection{Development trend of natural gas power generation industry in China}

From the point of view of the development trend of China's natural gas power generation industry, affected by multiple favorable and unfavorable factors, it is expected that the development of large cogeneration will slow down in the future, and the natural gas peak-shaving power plant will have a certain development space. It is expected that by 2022, the installed capacity of natural gas in China will exceed 110 million kilowatts, the proportion of gas and electricity will reach 5.2 percent, and the electricity generated by natural gas will reach 419.1 billion kilowatts. In the same year, the installed scale of natural gas distributed energy is expected to reach 38.9 million kilowatts and centralized to 75.79 million kilowatts.

In addition, China's natural gas generation consumption is expected to reach 76.27 billion cubic meters in 2022, accounting for 20 percent of the natural gas consumption structure, up 2 percentage points from the current level.

\section{Problems existing in China's natural gas power generation industry}

Through the investigation of power generation enterprises, it is learned that although the natural gas power generation projects in China are progressing rapidly at present, there are also some factors hindering the development of natural gas power generation. It is mainly reflected in the following four aspects:

(1) Policy planning. At present, the development of natural gas power generation in most parts of China lacks systematic planning, and the related policies are scattered in energy policy and other power generation policies. The price policy of power generation realizes the linkage of gas and electricity. The main source of financial subsidy is the electricity price space between sales electricity price and online electricity price, and the tax preference is not reflected in the policy.

(2) The supply of gas sources. From April to October each year, the natural gas supply is relatively sufficient, and the natural gas generator set can maintain a relatively high load. After entering the heating season in November, the supply of natural gas is relatively tight, in addition to the peak unit and the unit that maintains the necessary heating, some units have to stop. Taking 2018 in Jiangsu Province as an example, only 2600 hours of power generation can be realized in 3500 of peak shaving units and 4500 hours in 5500 hours of cogeneration units.

(3) The problem of economic benefit. Compared with the electricity price of natural gas, the price of natural gas fluctuates more frequently in the past two years, and because the gas source can not be guaranteed, the number of hours of power generation can not reach the plan, which will lead to the increase of unit cost of electricity, which will also lead to the income lower than the reasonable profit considered in the electricity price calculated by the price department.

(4) Other issues. Because the natural gas power generation equipment still depends on the import basically, resulting in the depreciation cost of natural gas, the operation and maintenance cost is still relatively high. Natural gas, as an interruptible user with peak shaving function, the price of natural gas power generation gas does not reflect its value to the safety of pipeline network operation.

\section{Suggestions on promoting the healthy and rapid development of natural gas power generation industry in China}

\subsection{The orientation and goal of the Development of Natural Gas Power Generation Industry in China}

Natural gas power generation is an important part of China's natural gas development process, which is conducive to optimizing the primary energy structure of China and increasing the proportion of natural gas in China's primary energy. In 2030, the proportion of 
China's natural gas power generation in the whole country reached $8 \% 10 \%$, and the consumption of natural gas power generation in the lower reaches of natural gas in China reached $25 \% \leq 30 \%$. To perfect the policy environment for the investment and development of natural gas power generation in China, to form a fair and open system for the marketization of natural gas and power generation, to ensure the stability and diversification of gas sources, and to reduce the cost of gas sources. Pattern, looking for business model, pricing model innovation breakthrough.

\subsection{Suggestions for promoting the development of natural gas power generation industry}

(1) Clear objectives and orderly and rational development. Make clear the strategic goal and stage goal of natural gas, gas electricity development. Make clear the development goal of natural gas power generation and promote the rational development of industry in an orderly manner.

(2) Reduce the cost of gas source. We should speed up the process of marketization reform, advocate that gas and electricity enterprises buy natural gas directly from the upstream, open up the links of direct supply and direct purchase of natural gas power generation enterprises, and reduce the gas distribution cost of gas in intermediate cities, so as to effectively reduce the gas source cost of gas and electricity.

(3) The linkage of gas and electricity price. Through the linkage of gas and electricity price, a certain quota is given to natural gas to generate electricity, to ensure the online power of natural gas, and to effectively improve the power generation of gas and electricity.

(4) Speeding up the implementation of the reform of the electric power system. We will speed up the implementation of the reform of the power system, face users directly, and strive for economic space for natural gas.

(5) To strengthen the two-way peak-shaving effect between gas and electricity. It is suggested that there should be a complementary relationship between peak regulation of gas and peak regulation of electricity. For example, set up summer scenario mode: summer power generation more, north gas south; winter scenario mode: northern heating, south gas north, southern power generation using coal complementary adjustment.

\section{The conclusion}

The core problems affecting the development of natural gas power generation in China are the high gas price of natural gas and the shortage of natural gas power generation time. Based on the summary of natural gas power generation experience in typical foreign countries, this paper holds that the following seven points should be achieved to promote the development of China's natural gas power generation industry: clear objectives and orderly and reasonable development. Reduce the cost of gas sources. Gas and electricity price linkage.
Reasonable subsidies and lower taxes and fees. Speed up the implementation of the reform of the electric power system. Strengthen the two-way peak-shaving effect between gas and electricity.

\section{References:}

1. Liu, W.L. (2015)The course of marketization reform of British natural gas industry-also on the institutional conditions of third party access [J]. International Petroleum economy,23 (9) :62-68.

2. Liu, L.H., Zhong,S.M. ()Recent situation and prospect of natural gas power generation in China [J]. Gas turbine technology, (3):1-6.

3. Du, D.Y., Huang,H. (2013)Experience and enlightenment of natural gas power generation abroad [J]. Shanghai Gas, (2): 23-26.

4. Li, Q.Z.(2012) Preliminary Study on the Mechanism of On-grid Price for Natural Gas Power Generation[J]. Market Economy and Price, (11):14-16.

5. Cai L.J., Tao X.H. (2005)Application of gas cogeneration in industrial park [J]. District heating, 7 (1): 12-15.

6. Liu ,W., Ge,B., Leng W.(2014) Research on the present situation and related problems of Gas Power Generation in Jiangsu Province [J]. Gas turbine technology, 27 (1): 6 -10. 